\title{
DIE PENNESTRYD TUSSEN DIE CHRISTENE EN HEIDENE GEDURENDE DIE EERSTE DRIE EEUE NA CHRISTUS.
}

In sy boek „Die Geskiedenis van die Nederduits Hervormde Kerk van Afrika", beskrywe professor S. P. Engelbrecht op treffende wyse hoe die Afrikaners in die Kaap-Kolonie gedurende die tweede helfte van die neëntiende eeu met die geestelike swaard vervolg is. ${ }^{1}$ ) Dit is nie die eerste en ook nie die laaste keer dat lede van die Kerk op hierdie wyse beveg is nie, want die pennestryd teen die Christendom is so oud as die Christendom self. Die doel van hierdie artikel is om kortliks na te gaan watter aanvalle die Christene gedurende die eerste drie eeue van die kant van die heidene geleerdes ondervind, en hoe hulle daarop reageer het.

Die heidense letterkunde tot ongeveer die middel van die tweede eeu bevat besonder min verwysings na die Christendom. Die bekendste is dié van Tacitus waarin dit as 'n verderflike bygeloof wat in Rome posgevat het, beskryf word.") Volgens Tacitus is die Christene reeds in die dae van Keiser Nero (54-68) van kindermoord, kannibalisme en ontug beskuldig. Uit Christelike geskrifte weet ons dat die heidene verder ook die leerstellings van die Bybel kritiseer, en veral teen die goddelike natuur van Christus beswaar gemaak het. As gevolg van hul eie bygeloof het hulle Christus se wonderwerke nie verwerp nie maar beweer dat hulle deur middel van towerkuns verrig is. $\left.{ }^{3}\right)$

1) Op. cit. p. $11 \mathrm{sq}$.

$\Rightarrow$ Tacitus Hist. V. 3-5 en A.if XV 44, 3-4.

3) Justinus Apologia 1.30; Tertullianus Apologia 22. 
Tot ongeveer $176 \mathrm{na} \mathrm{Chr}$. is aantygings van hierdie aard tot vervelens toe herhaal, sonder dat enige heidense geleerde die moeite gedoen het om 'n grondige studie van die Christendom te maak. In daardie jaar het die heidense filosoof Celsus egter die pen teen die Christendom opgeneem en 'n werk geskryf wat hy die "Ware Woord" genoem het.

Ons besit slegs brokstukke van hierdie verbitterde twisgeskrif.4) Die inhoud daarvan was die resultaat van noukeurige waarneming van die Christendom se doen en late en 'n wetenskaplike ontleding van die Bybel en Christelike geskrifte. Van Celsus se persoon en lewe weet ons feitlik niks, behalwe dat hy 'n kultuurmens en 'n groot geleerde was. Uit die fragmente van sy werk blyk dit verder dat hy 'n ware Griek was wat onkunde versmaai, en die Christene geminag het omdat hy gedink het dat hulle sonder kultuur en geleerdheid was. Volgens hom het die Christene hulle daarop beroem dat hulle nie beskaafde mense uitgenooi het om by hul geledere aan te sluit. Hy kon nie verstaan waarom hulle begaan was oor die skuim van die samelewing nie, en het daarvan afgelei dat onnoseles, uitvaagsels, vrouens, kinders en slawe die enigste persone was wat hulle wou en kon bekeer (III. 44). Verder het hy beweer dat die Christene 'n verderflike invloed op die jeug uitgeoefen het deur geleerdheid te verdoem en onkunde aan te moedig (I. 9). Hulle is bestempel as ontrou aan die instellings van hul voorvaders sodat dit beter sou wees dat hulle almal sterf en van die aarde verdwyn (VIII. 54). Volgens Celsus het die Christene hulle aan godslastering skuldig gemaak deur God voor te stel as 'n god van woede (IV. 71), wat sonde in die wêreld toegelaat en hom later weer oor die boosheid van die mensdom berou het (VI. 53). Soos die meeste van die onbekeerde Grieke was Celsus besonder onsimpatiek teenoor Christus. Hy het Hom beskou as 'n onegte kind wat uit armoede na Egipte gevlug het. Daar sou $\mathrm{Hy}$ dan kennis van die towerkuns opgedoen het, wat Hom in staat gestel het om wonderwerke te verrig (I 28; 46; 68). Hy het verder beweer dat Christus se gedrag op aarde nie ooreenstem met dié van 'n koning of 'n held, om nie eers van 'n god te praat nie (I. 61; 62; 66). As hy 'n god was sou hy nie as 'n gevangene weggelei geword het nadat hy deur sy dissipels in die steek gelaat en verraai is nie (II. 9; V.58). Die hele idee van 'n lydende saligmaker was vir Celsus iets afstootliks en hy het die spot daarmee gedrywe dat Pilatus en diegene wat die Christene vervolg het, nie deur God gestraf is nie (VIII. 39).

Die gevaarlikste aspek van Celsus se aanval op die Christendom was sy kritiek op die Bybel en die Apokriewe Boeke, waarvan hy in deeglik kennis gehad het. In verband met die profesieë oor Christus

4) Die brokstukke is bevat in Origenes se werk Contra Celsum. Nommers in die teks verwys na hierdie werk. 
se koms wat in die $\mathrm{Ou}$ Testament aangetref word, het Celsus beweer dat hulle ook op ander persone betrekking kon hê, aangesien Christus in geen opsig van ander mense verskil het nie (VI. 75). Hy het ook die aandag daarop gevestig dat die skrywers van die vier Evangelies mekaar op verskillende punte teengespreek het (V. 52) en dat Moses en Christus se leerstellings nie ooreengestem het nie. (VI. 29).

Uit hierdie paar grepies uit Celsus se kritiek.i) behoort dit te blyk dat sy vernaamste oogmerk was om alles wat die Christene as heilig beskou het, te bespot en belaglik te maak. Hy het geen geheim van sy haat vir die Christene gemaak nie, en het openlik verklaar dat hulle soos misdadigers gestraf moes word (VIII. 54).

Celsus was een van die gedugte, indien nie die mees gedugte teenstander van die Christendom in die oudheid nie. Sy enigste waardige opvolger was Porphyrius. Teen die einde van die derde eeu het hierdie wysgeer, wat een van die vernaamste voorstanders van die Neoplatonisme was, die pennestryd teen die Christendom voortgesit. Net soos sy groot voorganger, het Porphyrius die tradisionele anti-Christelike argumente verwerk en belangrike oorspronklike bydraes daartoe gelewer. Sy kritiek was bevat in vyftien boeke, Contra Christianos (teen die Christene), wat ook nie in hul geheel bewaar gebly het nie.")

In teenstelling met die meeste van sy voorgangers, het Porphyrius die Christene nie meer van onsedelike gedrag beskuldig nie, en ook nie vir Christus as 'n towernaar beskou nie. Sy vernaamste doel was om die geloofwaardigheid van die Bybel te ondermyn. Hy het 'n deeglike studie van die Bybel gemaak, en sy kritiek bewys dat die fynste besonderhede sy aandag geniet het. So het hy bv. in verband met die opstanding uit die dood gevra of die gestorwenes soos Christus of soos Lazarus sou opstaan.') Vir Christus self het Porphyrius respek gehad, maar hy het beweer dat Christus se leerstellings deur sy dissipels verdraai en verkeerd interpreteer is. Hy het dit as 'n heel natuurlike ontwikkeling beskou, aangesien die dissipels volgens hom ongeletterde skaapwagters was. ${ }^{8}$ )

Die mees gedugte aspek van Porphyrius se aanval was sy Bybelkritiek. Die profetiese boeke van die Ou Testament het sy spesiale aandag geniet. In verband met die boek Daniël het hy bv. beweer dat dit nie deur Daniël geskryf is nie, maar deur 'n persoon wat in die tyd van Antiochus Epiphanes geleef het toe die dinge wat hy beskryf. plaasgevind het. Die boek bevat dus nie voorspellings van die toe-

i) Vir verdere kritiek van Celsus vgl. bespreking van Origenes verder aan.

i) Vir 'n versameling hiervan vgl. A. Harnack, ,Porphyrius gegen die Christen' Berlyn 1916.

i) Cf. J. Geffcken Zwei Griechische Apologeten. Leipzig 1907, p. 300.

s) Aug. De Cons. Evang. I. 23: Hieron. Ep 130. 
koms soos die skrywer voorgee nie. $\left.{ }^{9}\right)$ Porphyrius het die aandag hier gevestig op 'n probleem wat vandag nog nie bevredigend opgelos is nie.

Die algemene indruk wat deur die brokstukke van Porphyrius se werk geskep word is dat hy vasberade was om die nuwe geloof 'n gevoelige hou toe te dien en nie net geskrywe het omdat dit in die mode was om die Christene te kritiseer nie. Ongelukkig is dit onmoontlik om die verlore werk in sy geheel te rekonstrueer. Die feit dat die Christene baie min van sy kritiek op die Nuwe Testament en die grondbeginsels van die Christendom weerlê het, is ongetwyfeld 'n bewys dat hierdie gedeelte van sy kritiek baie moeilik weerlê kon word en dat hulle nie daarin opgewasse was nie.

In die begin van die vierde eeu het Keiser Konstantyn beveel dat alle eksemplare van die gevreesde Contra Christianos vernietig moes word. Die bevel het egter nie die verlangde uitwerking gehad nie sodat dit in die vyfde eeu herhaal is. ${ }^{10}$ )

Gedurende die finale stryd tussen die heidendom en die Christendom was die werke van Celsus en Porphyrius die vernaamste bronne waaruit die heidene hul propaganda teen die Christendom geput het. Selfs die grootste teenstander van die Christendom in die vierde eeu, Keiser Julianus die Afvallige, het die meeste van sy argumente teen die Christendom uit die geskrifte van hierdie twee heidene oorgeneem. Daar kan dus tereg beweer word dat die pennestryd teen die Christelike geloof sy hoogtepunt gedurende die tweede en derde eeu bereik het.

Ten einde die aandeel van die Christene in die stryd teen die heidene te begryp, is dit nodig om tot in die dae van die Apostels terug te gaan. Toe die Apostels bv. na die uitstorting van die Heilige Gees in vreemde tale begin praat het, het sommige van die toehoorders gespot en gesê dat hulle vol soetwyn was. Petrus het derhalwe aan hulle verduidelik dat die mense nie dronk was nie maar dat die voorval 'n vervulling van die profesie van die profeet Joël was.'") In Paulus se rede op die Areopagus in Athene, vind ons in kort en bondige samevatting van die geestelike stryd en die metodes wat die Christene vanaf die vroegste tye toegepas het. Eerstens word daar na die dwaasheid van die afgodediens verwys: "Die God wat die wêreld gemaak het en alles wat daarin is. Hy wat Here van hemel en aarde is, woon nie in tempels wat met hande gemaak is nie. Ook word Hy nie deur mensehande gedien asof $\mathrm{Hy}$ an iets behoefte het nie: ... As ons dan die geslag van God is moet ons nie dink dat die godheid aan goud of silwer of steen of die beeldwerk van menslike

\footnotetext{
9) Hieron. CoM- IN DAN. XII-5 sq.

10) Socr. H.E. I-9 en Codex Just. I 1-3 en I 5-6.

${ }^{11)}$ Handelinge II. 13-17.
} 
kuns en uitvinding gelyk is nie."'12) Die ander kenmerk van die Christene se houding was die neiging om punte van kontak met die heidene te vind en hulle dan te gebruik om laasgenoemdes se belangstelling gaande te maak. Dit blyk duidelik uit Paulus se verwysing na die altaar wat die Atheners aan die onbekende God gewy het. ${ }^{13}$ )

Net soos Petrus en Paulus het die Christene hulle of fensiewe sowel as defensiewe metodes in die stryd teen die heidene toegepas. Gedurende die eerste twee eeue was dit veral nodig om aantygings teen die gedrag van die Christene in hul daelikse lewe en omgang met mekaar te weerlê. Daarna was die beskuldigings minder persoonlik en meer teen die Christelike leerstellings gemik. Ten spyte hiervan kan sekere kenmerke in die geskrifte van die Christelike apologete vanaf die dae van die apostels tot in die vyfde eeu na Christus nagespoor word.

Ons vind b.v. dat aantygings teen, en veroordeling van die heidense godsdiens gewoonlik sonder enige oorspronklikheid herhaal is. ${ }^{1.1}$ ) Die onsedelikheid van die heidense gode en hul aanbidders is gedurig beklemtoon en met die voorbeeldige lewe van die Christene vergelyk. ${ }^{15}$ ) Netsoos die Stö̈synse filosowe het die Christene die skepping van God bewonder en geprys, maar dan het hulle daarop gewys dat die heidene nie die Skepper nie, maar hemelliggame wat hy gemaak het, aanbid het $\left.{ }^{16}\right)$ Wat die heidense filisofie betref, het hulle aangetoon dat die filosowe nooit daarin geslaag het om hul leerstellings toe te pas, en die mensdom te verbeter nie. ${ }^{17}$ ) Daarenteen het hulle nie geaarsel om sekere heidense wysgere se teorieë te gebruik om die gebreke van die heidense godsdiens aan die kaak te stel nie. Ten opsigte van die redenaarskuns was die Christene netso inkonsekwent. Alhoewel hulle welsprekendheid afgekeur, en die eenvoud van die Bybelse taal geprys het, was die meeste van hulle tog besonder gesteld op hul eie taal en styl. ${ }^{18}$ )

Maar om terug te kom tot die inhoud van die apologete se geskrifte: Die heidense heersers is gewoonlik daarvan beskuldig dat hulle die Christene op grond van hulle goddeloosheid vervolg het, terwyl talle heidense filosowe wat die afgodediens bespot het, in vrede gelaat is. ${ }^{19}$ ) 'n Aanklag waaraan ook baie aandag geskenk is, was dat die Christendom veel jonger as die heidense godsdienste was. Die Christene het daarop gewys dat die Joodse godsdiens, waaruit die Christendom voortgespruit het, veel ouer as die Griekse kultuur

12) Ibid XVII. 25-29.

13) Ibid XVII. 23.

11) Vgl. Aristides XVII. 2: Athenagoras XXXII sq. ens.

15) Just Apor. I. 14: Tert Apol. 39.

16) Athenag. IV, XV. Vgl. Cicero De Natura Deorum II. 5.15. Ook Clemens Alexandrinus Protr. V. 65, en Arnobius III. 35.

ii) Theoph. III. 3.7.

18) Tust Apol. I. 60.11: Tatianus 32 sq.; Tert. A pol. 46.47.

19) Tert. Apol. XLVI. 4. 
was. Hulle het selfs beweer dat die Grieke baie van hul leerstellings van die Jode oorgeneem, en dat Plato uit die Ou Testament plagiaat gepleeg het. ${ }^{2 \text { ") }}$ 'n Ander argument wat herhaaldelik aangevoer is, was dat die getalle van die Christene ten spyte van die vervolginge met rasse skrede toegeneem het. ${ }^{21}$ )

Die Christelike skrywers het hul argumente teen die heidense godsdiens meestal oorgeneem uit die geskrifte van die groot aantal nie-Christelike geleerdes wat die veelgodediens vanaf die vroegste tye aangeval en veroordeel het. Oor die algemeen was die Christene aanvanklik glad nie tuis in die massas literatuur oor hierdie onderwerp nie. Ten einde die skyn van geleerdheid te verwek, het baie van hulle soms hul werk oorlaai met aanhalings wat hulle self nie begryp het nie. Namate die intellektuele standaard van die Christene opgehef is, het hul gebruik van die ou bronne al meer oordeelkundig en oortuigend geword. Gedurende die eerste drie eeue was die Christelike letterkunde egter nog in sy kinderskoene en al die Griekse apologete in hierdie tyd het, om Geffken se woorde te gebruik, tot die ,apologetische Plebs" behoort. ${ }^{22}$ ) Ons dink hier aan skrywers soos Aristides, Justinus die Martelaar, Tatianus, Athenagoras, Theophilus, Clemens Alexandrinus en Origenes. Dis is die moeite werd om stil te staan by Origenes se weerlegging van Celsus se aanval op die Christendom.

Origenes is in 184 na Chr. in Alexandrië gebore. Sy ouers was Christene, en sy vader is weens sy geloof onthoof. Vanaf die jare van sy jeug was Origenes 'n ywerige Christen en hy het sy hele lewe aan sy geloof gewy. Hy was ongetwyfeld die grootste Christelike geleerde en skrywer van die eerste drie eeue. ${ }^{23}$ )

Sy werk teen Celsus (Contra Celsum) het uit agt boeke bestaan en is tussen die jare 246 en 248 geskryf, d.w.s. toe hy al oor die sestig jaar oud was. Die metode wat Origenes toegepas het, was om sy teenstander se argumente puntsgewys te weerlê. Die gevolg hiervan was dat hy soms te veel oor onbelangrike punte uitgewei en nie die algemene strekking van argumente gesnap het nie. Die werk as geheel laat gevolglik die indruk van onsamehangendheid. terwyl baie van sy verklarings nie oortuigend is nie. Op Celsus se beswaar teen die maagdelike geboorte van Christus, het hy bv. geantwoord: Sommige vrouelike diere plant hul geslagte voort sonder manlikes. Temér, die Grieke glo dat die eerste mens wat geskape is, uit aarde ontstaan het. Soiets is meer ongehoord as dat Christus gedeeltelik op dieselfde

2ii) Origenes Contra Celsum I. 2.

20) Tert. Apol. XXXVII. 4; Clemens Alex. Strom. VI. 18.167: Origenes CoNtra Celsum I. 3; 26 en VII. 26.

2) J. Geffcken, "Zwei Griechische Apologeten," p. 267

23) Vir meer oor Origenes vgl. .,Wilhelm von Christs Geschichte der Griechischen Litteratur" verwerk deu Schmid-Stählin. Munchen 1924, p. 1317 sq. 
wyse as ander mense in die lewe gebring is. (1. 37) Celsus se bewering dat die voorspellings van Christus se koms op ander persone betrekking kon hê, het hy probeer weerlê deur na Miga V. 1 te verwys, waarin voorspel word dat daar uit Bethlehem een sal kom wat 'n heerser in Israel sal wees. Die aanwesigheid van die krip in Bethlehem, waarin die kind Jesus gelê het, was vir hom 'n afdoende bewys dat die voorspelling vervul is en op niemand anders toegepas kon wees nie (I. 6)

Origenes het dikwels onnodig veel aandag aan onbelangrike punte bestee. Celsus het volgens hom verklaar dat Christus deur sy dissipels verraai is terwyl daar in werklikheid net een verraaier was. Dan sou Celsus ook beweer het dat Christus se volgelinge matrose i.p.v. vissers was (I. 62). Celsus se verklaring dat hy boeke oor die toorkuns by Christene gesien het, het hy eenvoudig as ' $n$ infame leuen bestempel (VI. 40). Celsus het die Christene en Jode met wurms en paddas vergelyk. In in lang betoog het Origenes aangetoon dat so 'n vergelyking onvanpas was (IV. 24).

In meer as een geval het Origenes egter die spyker op die kop geslaan. Op die aanklag dat Christus in towenaar was, het hy geantwoord dat nie een van die gewone towenaars se wonderwerke ooit sedelike opheffing en redding van siele ten doel gehad het nie (I. 68; II. 50). Interessant is ook sy histories-filologiese standpunt ten opsigte van die Bybel. Hy het aangetoon dat dit onmoontlik was om die waarheid van alle geskiedkundige feite te bewys. Persone wat geskiedenis met in goeie gesindheid lees, besluit gewoonlik wat letterlik opgeneem en wat figuurlik verklaar moet word. Netso in die geval van die verhale in verband met Christus het die lesers welwillendheid nodig, en moet hulle probeer om uit te vind wat die skrywers se bedoeling was (I. 42). Daar moet by hulle die bereidwilligheid wees om sekere dinge sonder bewyse aan te neem en te glo. Ook moet 'n verhaal nie in die geheel verwerp word omdat onbelangrike onderdele daarvan onaanneemlik lyk nie.

„Wie," het Origenes gevra, ,sal beweer dat die Trojaanse oorlog nie plaasgevind het omdat ongelooflike verhale soos dié van Achilles, die seun van 'n seegodin en 'n mens, daaraan vasgeknoop is nie?" (I. 42). Celsus het die Christendom geminag omdat dit uit onverstandige mense sou bestaan. Hierop het Origenes verduidelik dat die Christene die standpunt ingeneem het van 'n mensliewende geneesheer wat krankes opsoek om hul lot te verbeter. As die Christene ongeletterdes en armes van gees wil bekeer, verlang hulle nie noodwendig dat die groot gros van Christene uit sulke mense moet bestaan nie. Inteendeel is hulle ook gretig om skerpsinniges wat die verborgenhede van die Skrif kan verstaan, te bekeer (III. 73-74). 
Celsus het die Jode as Egiptiese wegloper-slawe wat nooit iets noemenswaardig verrig het nie. bestempel. Hierop het Origenes gevra waarom hulle dan 'n eie taal i.p.v. diē van die Egiptenare gehad het. As hulle die gehate Egiptiese taal nie meer wou praat nie, sou hulle waarskynlik die taal van hulle bure aangeneem het, i.p.v. Hebreeus, wat nêrens anders in die wēreld voorkom nie (IV. 31). Alhoewel die Jode nie in die Griekse geskrifte genoem is nie, het hul staatsinrigting en wette bewys dat hulle mense was wat die hemelse lewe op aarde probeer weerspieël het. Hulle was voorstanders van waarheid en regverdigheid, het die wysbegeerte beoefen, en het Sabbatte en spesiale feesdae vir Godsdienstige sake opsy gesit (IV. 31). Wat die skandelike verhale in die Bybel betref, het Origenes beweer dat daar, in vergelyking met die onsedelike en belaglike mites van die Grieke, niks in die Bybel is waaroor die Christene hulle behoort te skaam nie. Hy het na al die egbreuk, vader en kindermoord en bedrog van die heidense gode verwys. Daar is egter gedeeltes van die Bybel wat sonder twyfel geskryf is met die bedoeling dat hulle figuurlik verklaar moes word. Daarom het die Psalm-digter tot God gebid: „Open my oë dat ek kan sien die wonders uit U werk” (IV. 48-50; Psalm 119:18)

Origenes se grootste krag moet egter in sy geloof gesoek word. Celsus het ook sy godsdiens in 'n ernstige lig beskou, maar wat geloofsywer betref is hy deur Origenes totaal oorskadu. Luister na sy antwoord op die aanklag dat Christus 'n gewone mens was; Ek weet nie of 'n mens, wat dit gewaag het om sy onderrigen opvattings oor die hele bewoonde wêreld te versprei, in staat is om sy wil sonder God uit te voer en om sterker te word as almal wat die verspreiding van sy leer teegaan nie. Hoe sou die menslike natuur so 'n groot menigte van teenstanders kan oorweldig as daar nie iets sterkers in was nie? Maar aangesien die vermoë van God in Christus was, asook die wysheid van die Vader, het $\mathrm{Hy}$ dit alles gedoen en doen $\mathrm{Hy}$ dit nog steeds (II. 79). Hierdie woorde openbaar nie alleen 'n onwrikbare geloof nie, maar ook 'n vaste oortuiging dat die Christendom spoedig sou seëvier.

Alhoewel Origenes baanbrekerswerk verrig het, het die Romeinse Christene wat aan die pennestryd teen die heidendom deelgeneem het, meer durf en geesdrif as die Grieke aan die dag gelê. Ons dink bv. aan Tertullianus, 'n Romeinse burger uit Kartago, wat teen die einde van die tweede eeu ' $n$ apologie vir die Christendom geskryf het. Een van sy argumente was bv. dat Christene nie misdadigers kon wees nie, aangesien daar nog nooit 'n misdadiger was wat nie probeer het om sy misdade te verberg nie maar trots was daarop. „Watter soort misdaad is dit," het hy gevra, ,wat nie een van die gewone kenmerke van 'n misdaad soos vrees, skaamte, berou en verdriet besit nie?"21)

24) Tert. ApOL. I. 13. 
'n Ander Romeinse Christen uit hierdie tydperk was Minucius Felix, die skrywer van die interessante werkie getitel Octavius. Hy het die Romeine o.a. daaraan herinner dat die s.g. voorspoed wat die heidense gode vir Rome besorg het, met bloedige oorloë, roof en plunder gepaard gegaan het ${ }^{2.5}$ ).

Gedurende die eerste drie eeue van ons jaartelling het die geestelike stryd na die uiterlike beoordeel, in die heidene se guns verloop. Een opsig waarin die Christene hul teenstanders deurgaans oortref het, was die ywer en vasberadenheid waarmee hulle gestry het. Daar was egter geen Christene met genoeg kennis en oorspronklikheid om die heidense kritiek op bevredigende wyse te weerlê nie. Maar gedurende die volgende twee eeue het die stryd 'n nuwe wending geneem. Nie alleen het die Christendom aan die einde van die vierdie eeu onder Keiser Theodosius die staatsgodsdiens van die Romeinse Ryk geword nie. maar die Christene het hul heidense tydgenote ook op die gebied van die letterkunde en geleerdheid in die algemeen totaal oorskadu. 